\title{
Blanket disapproval of all unlicensed indications is wrong
}

\section{Stephen J Evans professor of pharmacoepidemiology}

London School of Hygiene and Tropical Medicine, London WC1E 7HT, UK

"Off-label" covers a variety of situations. Applications for marketing authorisations-licences that lead to a "label"-are made by companies for almost entirely commercial reasons. The company that makes bevacizumab does not apply for an authorisation for use in macular degeneration because it also makes the more expensive licensed product.

This is a failing of the licensing system, in that it relies on companies to do things in the best interests of patients because these usually coincide with their commercial interests. In this situation, they do not.

The General Medical Council and Kyle mistakenly disapprove of all unlicensed indications. ${ }^{1}$ If it were open (practically and legally) to the NHS to apply for a marketing authorisation, bevacizumab would probably become licensed for this indication, but with pressure from companies and their allies to prevent this, the opportunity to benefit more patients will be lost.

Competing interests: None declared.

SJE is a member of the pharmacovigilance working party at the European Medicines Agency but this is strictly a personal view.

1 Kyle G. Prescribing bevacizumab off-label contravenes GMC advice. BMJ2011;343:d7131. (8 November.)

Cite this as: BMJ 2011;343:d7726

๑ B BMJ Publishing Group Ltd 2011 